(n)

\title{
Actions of endocrine-disrupting chemicals on stem/progenitor cells during development and disease
}

\author{
Elizabeth Kopras*, Veena Potluri*, Mei-Ling Bermudez*, Karin Williams, Scott Belcher ${ }^{1}$ \\ and Susan Kasper
}

Department of Environmental Heath, University of Cincinnati, 3223 Eden Avenue, Cincinnati, Ohio 45267-0056, USA ${ }^{1}$ Department of Pharmacology and Cell Biophysics, University of Cincinnati, Cincinnati, Ohio 45267-0575, USA

*(E Kopras, V Potluri and M-L Bermudez contributed equally to this work)
Correspondence should be addressed to S Kasper

Email susan.kasper@uc.edu

\begin{abstract}
Development and fate of the stem cell are regulated by extrinsic signals from the environment. Endocrine-disrupting chemicals which perturb hormonal signaling in utero and during early childhood may cause deregulation of multiple developmental processes, ranging from breakdown of stem cell niche architecture, developmental reprograming and altered stem cell fate to impaired organ and gonad development and sexual differentiation. Therefore, study of the environmental effects on stem cell integrity and normal development is a new and emerging focus for developmental biologists and cell toxicologists. When combined with new human and mouse stem cell-based models, stem cell differentiation dynamics can be studied in more biologically relevant ways. In this study, we review the current status of our understanding of the molecular mechanisms by which endocrine disruptors alter embryonic stem cell and adult stem/progenitor cell fate, organ development, cancer stem cell activity, and tumorigenesis.
\end{abstract}

\section{Key Words}

- endocrine disruptors

- stem cell/progenitor cell

- cancer stem cell

- organ development

- steroid hormone receptors

\section{Introduction}

Endocrine disruptors are naturally occurring or manmade compounds that interfere with normal hormonal function (Birnbaum 2013). Mounting evidence from epidemiological and animal-based studies indicates that exposure to these chemicals in utero and during early life could result in birth defects, behavioral disorders, and cancer. Indeed, exposures to endocrine-disrupting chemicals (EDCs) during this critical time of growth and development could result in genetic modifications which are passed down to subsequent generations. To date, our knowledge on the mechanisms by which EDCs may cause these deleterious effects at the cellular level remains limited. In this study, we review cell-based studies which have investigated the mechanisms by which EDCs modulate embryonic and adult stem cell function and cancer stem cell (CSC) activity (summarized in Fig. 1).

\section{Susceptibility of embryonic stem cells to EDC exposure}

A number of human embryonic stem (hES) cell lines have been derived from the inner cell mass of blastocyst-stage human embryos. These cells are pluripotent, that is, capable of differentiating into the three primary germ layers, including ectoderm, endoderm, and mesoderm. Therefore, they have been considered as a source of various cell types for organ regeneration or tissue replacement after injury or disease (Odorico et al. 2001). It has also been postulated that hES cells could be used

Published by Bioscientifica Ltd

This paper is one of three papers that form part of a thematic review section on

Endocrine Disruptors and Gancer. The questeditor for this section was. Gail Risbridger ${ }_{B}: 30: 09 \mathrm{AM}$

Monash University, Australia via free access 


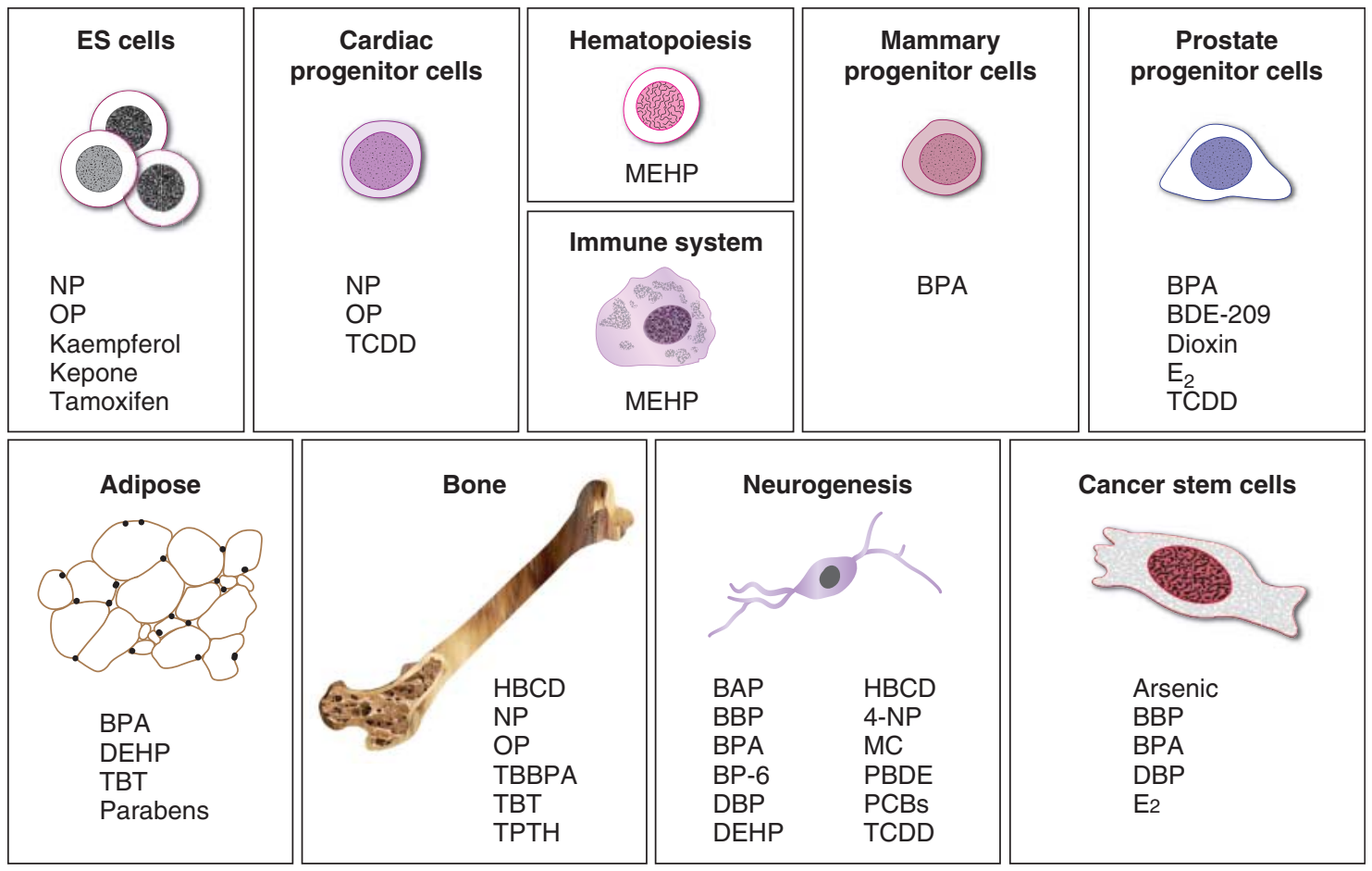

\section{Figure 1}

Schematic representation of stem, progenitor, and cancer stem cells and the primary organ systems which are susceptible to EDC exposure. Abbreviations for the specific endocrine disruptors modulating each

for reproductive toxicity screening in vitro (Krtolica \& Giritharan 2010) as well as for drug discovery to minimize unexpected toxicity when entering a clinical trial (Jensen et al. 2009). Using undifferentiated hES cells in an in vitro screening assay, Kim et al. (2006) reported that exposure to the organic compounds such as nonylphenol (NP) and octylphenol (OP) decreased expression of Oct4 and Nanog in a dose-dependent manner. As Oct4 and Nanog are transcription factors required for maintaining stem cell pluripotency and self-renewal, it is likely that NP and OP decrease hES pluripotency. Furthermore, NP and OP were cytotoxic, inducing DNA fragmentation and hES cell death through Fas-Fas ligand interactions and caspase-3 and -8 activity (Kim et al. 2006). Interestingly, hES cellderived neural progenitor cells showed greater sensitivity to NP and OP exposure, possibly through the downregulation of ATP-binding cassette transporters known to pump out toxicants (Kim et al. 2006).

Several other hES cell lines, H1, H9, and BGN1, show heterogeneity in that they consist of at least two distinct cell types; a large cell type which differentiates in response to retinoic acid and a small cell type which retains its stem cell characteristics (Annab et al. 2012). Large and small cell cell type and organ system are listed as indicated. The chemical names for these abbreviations are provided in the text of the manuscript.

types in both $\mathrm{H} 1$ and $\mathrm{H} 9 \mathrm{hES}$ cells exhibited differential responses when exposed to estrogenic EDCs. Tamoxifen and kaempferol decreased SSEA-3 expression in the large cell type only, suggesting that they promoted hES differentiation. Kepone decreased SSEA-3 expression in both large and small cell types, implying that Kepone promoted differentiation in large cells and inhibited pluripotency in small cells. In contrast, apigenin increased SSEA-3 expression in both cell types, suggesting that this toxicant promoted pluripotency (Annab et al. 2012).

Collectively, these studies indicate that exposure to endocrine disruptors alters the stem cell characteristics of hES cells at multiple levels. EDCs could induce hES cell differentiation, thereby impairing the developmental process. Alternatively, they could maintain the expression of stem cell proteins to promote pluripotency (Annab et al. 2012). Furthermore, the degree of responsiveness to EDC exposure is dependent on developmental stage. These observations offer new perspectives for understanding the fundamental mechanisms underlying the EDC-induced effects on hES cells. Furthermore, they could contribute to the development of new predictive screening assays for the hazard assessment of developmental toxicity.

Published by Bioscientifica Ltd. 


\section{Susceptibility of germ cells to EDC exposure}

Sex determination and sexual differentiation in humans are preset to follow the female pathway of development (Sharpe 2006). Development into a phenotypic male is hormone-dependent, in which hormones divert development from the female pathway, resulting in masculinization and sexual differentiation. Thus it appears that male development would inherently be more susceptible to endocrine disruption through exposure to exogenous chemicals with hormonal properties (Sharpe 2006). Epidemiological studies suggest that disruption of the hormonal microenvironment during gonad differentiation could result in developmental deficiencies and problems later in life, including cryptorchidism, hypospadias, decreased spermatogenesis, hypogonadism, and testicular germ cell cancer. Germ cells reside within a microenvironment or 'niche' composed of Sertoli cells, Leydig cells, and peritubular myoid cells which produce hormonal and paracrine factors required for germ cell growth and maturation (Kristensen et al. 2008). Disruption of the niche could have profound effects on sperm development and it is likely that the niche cells would serve as targets for the activity of endocrine disruptors (Fig. 2).
The germ cell niche is created through the formation of tight junctions between germ cells and Sertoli cells of the testicular seminiferous epithelium (Yao et al. 2010). These actin filament-based anchoring junctions are important for the maintenance of physical contact between Sertoli and germ cells as well as for regulating the release of mature spermatids into the lumen (Yao et al. 2010). Di(2-ethylhexyl)phthalate (DEHP) could disrupt the physical association between Sertoli and germ cells, resulting in premature loss of germ cells from the seminiferous epithelium (Erkekoglu et al. 2012). Similarly, the active DEHP metabolite mono-(2-ethylhexyl) phthalate (MEHP) disrupted Sertoli-germ cell contact. In this process, the expression of occludin was decreased in the tight junctions between Sertoli cells and expression of laminin- $\gamma 3$ and $\beta 1$-integrin was decreased in the apical ectoplasmic specializations between Sertoli and germ cells (Yao et al. 2010). Furthermore, exposure to MEHP induced expression of the matrix metalloproteinase protein MMP2 and decreased expression of tissue inhibitor of metalloproteinase 2 (TIMP2) in a time-dependent manner. While these activities disrupted Sertoli-germ cell contact, cell detachment was independent of the process of apoptosis (Yao et al. 2009, 2010).

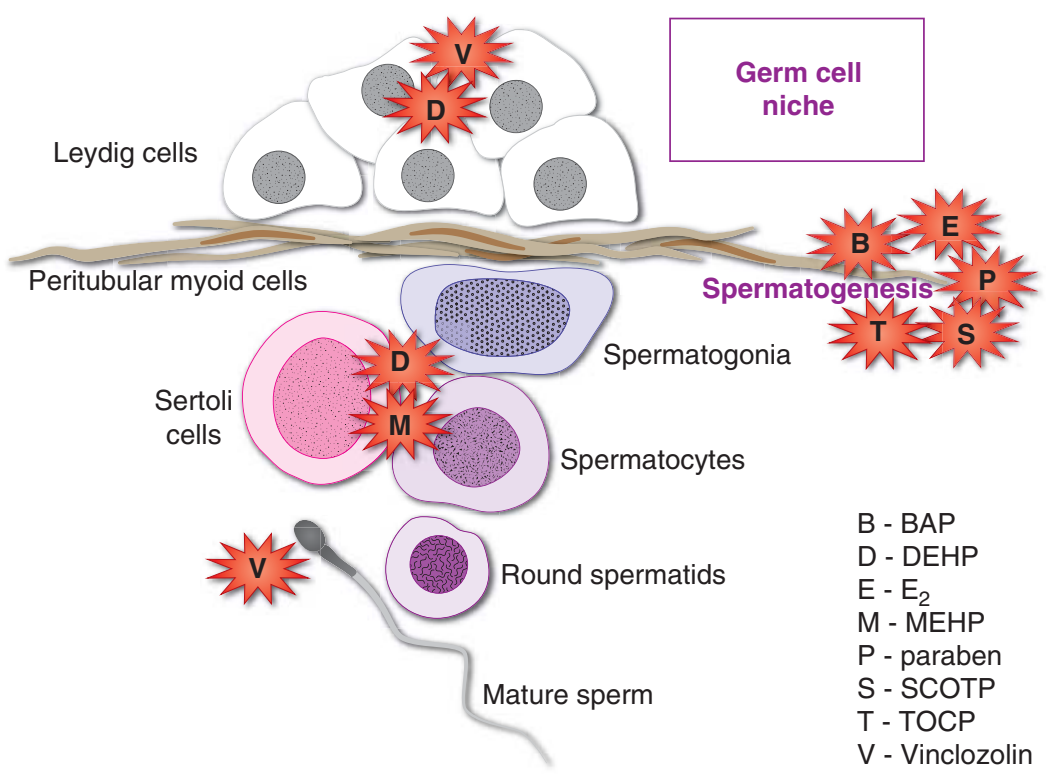

\section{Figure 2}

EDCs which disrupt germ cell niche homeostasis. Production of androgens by Leydig cells is downregulated by plasticizers (DEHP) (Zhang et al. 2008). The process of spermatogenesis is disrupted by estrogenic compounds (BPA, $E_{2}$ ), preservatives (paraben), and organophosphates (TOCP, SCOTP) (Ahn et al. 2012, Aoki \& Takada 2012, Chen et al. 2012). The physical contacts between Sertoli cells and germ cells are broken by exposure to plasticizers (DEHP, MEHP), resulting in premature loss of germ cells (Yao et al. 2010, Erkekoglu et al. 2012). The dicarboximide fungicide Vinclozolin is reported to induce epigenetic transgenerational changes in the sperm epigenome and to cause Leydig cell tumors in rats (Kavlock \& Cummings 2005, Guerrero-Bosagna et al. 2012). http://erc.endocrinology-journals.org DOI: 10.1530/ERC-13-0360
(C) 2014 Society for Endocrinology Printed in Great Britain
Published by Bioscientifica Ltd. 
Within the niche, Leydig cells produce testosterone for the developing germ cells (Zhang et al. 2008, Hu et al. 2009). DEHP exposure of both fetal and adult Leydig cells resulted in a biphasic effect. At lower doses, DEHP increased testosterone production either directly by stimulating testosterone production or by increasing the number of Leydig cells. At higher doses, DEHP inhibited testosterone production (Zhang et al. 2008). The fungicide Vinclozolin is an antiandrogenic compound that has been shown to cause Leydig cell tumors (Kavlock \& Cummings 2005). The peritubular cells produce leukemia inhibitory factor (LIF), a member of the interleukin 6 cytokine family known to mediate self-renewal of stem cells, including primordial germ cells and gonocytes (Piquet-Pellorce et al. 2000). LIF promotes proliferation of immature germ cells (Piquet-Pellorce et al. 2000). Whether LIF production is modulated by EDCs is not clear.

The common endocrine disruptor bisphenol A (BPA) adversely affects germ cell self-renewal. Using an in vitro embryoid body assay, Aoki \& Takada (2012) reported that exposure of undifferentiated mouse ES cells to BPA upregulated the expression of numerous germ cell markers (Stra8, Dmrt1, Vasa, Dazl, Sycp3, and Dmc1). Similarly, treatment with retinoic acid also induced germ cell differentiation; albeit by inducing Hoxa1, Rarb, and Cyp26b1 expression and not Sycp3 and Dmc1 expression (Aoki \& Takada 2012). In addition, expression of the testicular somatic cell markers Sox9 and Fgf9 decreased whereas expression of the ovarian somatic cell markers Foxl2 and Wnt4 increased (Aoki \& Takada 2012). Together, these observations suggest that environmental BPA could function as a morphogen which promotes germ cell differentiation through alternate mechanisms. Furthermore, the ability of BPA to alter the expression of genes related to gonad development suggests that BPA exposure could cause feminization of the developing gonads or male to female sex reversal.

In isolated mouse spermatogenic cells, exposure to the organophosphate compound tri-ortho-cresyl phosphate (TOCP) inhibited neuropathy target esterase (NTE) activity as measured by phenyl valerate hydrolysis (Chen et al. 2012). Furthermore, spermatogonial cell proliferation was inhibited by exposure to the active TOCP metabolite, saligenin cyclic-o-tolyl phosphate (SCOTP), as well as by NTE knockdown using shRNA technology. These results suggested that NTE regulated spermatogenesis and that exposure to TOCP could decrease the sperm count in mouse testes (Chen et al. 2012). The sperm genome may be furthermore modified through the transgenerational inheritance of epigenetic changes induced by EDC exposure. Transient exposure of F0 generation mothers to Vinclozolin resulted in the differential methylation of specific DNA promoter regions in the F3 generation sperm epigenome. Interestingly, these changes appeared to be species-specific, being observed in the outbred CD-1 strain, but not the inbred 129 mouse strain (Guerrero-Bosagna et al. 2012).

Recently, parabens have been shown to act as xenoestrogens in the ovary (Ahn et al. 2012). Exposure to high doses of butyl p-hydroxybenzoate (butyl-paraben) and propyl p-hydroxybenziate (propyl-paraben) increased the number of primordial follicles while decreasing the number of early primary follicles. Paraben activity increased anti-Müllerian hormone levels and expression of the transcription factor Foxl2; however, paraben decreased the expression of Star and Cyp11a1, thereby inhibiting the early phase of folliculogenesis in the ovaries of neonatal female rat. Similarly, estradiol $\left(\mathrm{E}_{2}\right)$-regulated Star and Cyp11a1 expression; however $\mathrm{E}_{2}$ did not affect Amh and Foxl2 expression. Thus in the ovary, parabens appear to regulate folliculogenic and steroidogenic genes through different estrogenic and nonestrogenic pathways (Ahn et al. 2012).

Together, these studies imply that all the cell types which comprise the germ cell niche, including the germ cells themselves, are susceptible to environmental chemicals which disrupt the hormonal equilibrium within the niche. Disruption of the niche has deleterious effects ranging from loss of Sertoli-germ cell contact and breakdown of the niche architecture, to deregulation of multiple processes including testosterone production, germ cell proliferation and differentiation, gonad development, and sexual differentiation.

\section{Susceptibility of progenitor cells to EDC exposure}

Progenitor cells are descendants of embryonic stem cells (ESCs) that are capable of differentiating into specific lineages (e.g., endocrine and neural) but do not express differentiated markers. Unlike that of stem cells, progenitor cells cannot divide indefinitely. However, progenitor cells remain susceptible to endocrine disruptors (Fig. 1); and altering progenitor cell number or function could modify many developmental and metabolic processes. The consequences of progenitor cells exposed to EDCs during neural development, skeletal formation, and bone remodeling, immune cell differentiation, cardiovascular tissue generation, mammary and prostate gland development, and adipogenesis are discussed below.

Published by Bioscientifica Ltd. 


\section{Disruption of neural development}

During neurogenesis, neuroepithelial cells go through symmetric and asymmetric cell divisions to generate stem-like neuroepithelial cells in addition to radial glial cells, neurons, and potentially basal progenitors as cellular intermediates (reviewed in detail by Gotz \& Huttner (2005)). Thyroid hormone (TH) is required for normal brain development throughout fetal life and early childhood. TH insufficiency during these developmental stages is known to influence cerebellum, neocortex, hippocampus, and corpus callosum development through mechanisms which reduce cell number, synaptogenesis, and dendritic arborization; to alter gene expression and cell migration patterns; and to decrease axonal myelination (reviewed in detail by Gilbert et al. (2012)). Thus changes in circulating TH or thyroid-stimulating hormone (TSH) could have profound effects on subsequent learning and memory function in the newborn and early childhood as well as in adult life (Gilbert et al. 2012). This has raised concern over the potential long-range effects of EDCs, which disrupt the thyroid/pituitary axis and cause decreased circulating TH levels.

Normal human neural progenitor (NHNP) cells were used to determine whether the polychlorinated biphenyl (PCB) compounds 2,3',4,4',5-pentachlorobiphenyl (PCB-118) and 3,3',4,4',5-pentachlorobiphenyl (PCB-126) interfered with TH-dependent neural differentiation (Fritsche et al. 2005). The three-dimensional neurosphere assay was used to evaluate PCB-118, PCB-126, and tri-iodothyronine $\left(\mathrm{T}_{3}\right)$ activity. Similar to $\mathrm{T}_{3}$ treatment, NHNP cells cultured on non-adherent culture plates formed floating neurospheres which contained an increased number of oligodendrocytes when exposed to PCB-118. Furthermore, the PCB-mediated effect on oligodendrocyte differentiation was inhibited by retinoic acid and by the TH-receptor antagonist NH-3 similar to that observed with $\mathrm{T}_{3}$ treatment. In contrast, PBC-126 was ineffective in promoting oligodendrocyte differentiation. Thus, these observations implied that PCB-118 mimicked $\mathrm{T}_{3}$ action via the TH pathway (Fritsche et al. 2005).

The activity of $\mathrm{TH}$ receptor (TR) can be inhibited by exposure to flame retardants (FRs). Exposure to $1,2,5,6,9,10$ - $\alpha$-hexabromocyclododecane (HBCD) suppressed TR $\beta 1$-mediated transcription by $55 \%$ in $\mathrm{CV}-1$ cells transfected with a F2-TRE-luciferase reporter gene (Ibhazehiebo et al. 2011a,b,c,d). Furthermore, HBCD inhibited dendrite development and arborization of primary Purkinje cells (Ibhazehiebo et al. 2011a,b,c,d). HBCD also suppressed TH-mediated neurite extension in isolated postnatal day 7 granule cells. This suppression could be rescued by brain-derived neurotrophic factor (BDNF), a TH-regulated protein which promoted granule cell development, suggesting that HBCD could disrupt TH-mediated brain development in part by inhibiting the $\mathrm{T}_{3}$-stimulated increase in BDNF expression (Ibhazehiebo et al. 2011 $a, b, c, d)$. Similarly, the polybrominated biphenyl mixture BP-6 could inhibit TH-induced dendrite arborization of Purkinje cells and neurite extension in granule cells (Ibhazehiebo et al. 2011a,b,c,d). Hydroxylated metabolites of polybrominated diphenyl ether were also shown to bind TR and inhibit transcription (Schriks et al. 2007, Kojima et al. 2009, Ibhazehiebo et al. 2011a,b,c,d).

The aryl hydrocarbon receptor (AhR) agonist BAP did not induce oligodendrite formation in NHNPderived neurospheres, implying that AhR signaling did not disrupt neural differentiation (Fritsche et al. 2005). However, in human cord blood hematopoietic stem cells (hUCBSCs), exposure to the polycyclic aromatic hydrocarbon 3-methylcholanthrene (MC) upregulated AhR expression and signaling while downregulating the expression of the neurogenesis-related transcription factor, cAMP response element-binding protein (CREB; Fritsche et al. 2005). Consequently, expression of stagespecific neuronal markers including nestin, neural cell adhesion molecule (NCAM), synaptophysin (SYP), 2-amino-3-(3-hydroxy-5-methyl-isoxazol-4-yl)propanoic acid (AMPA), and $N$-methyl-D-aspartate receptor subunit 2A (NR2A) were downregulated. However, neuronal marker expression could be rescued by knocking down AhR expression (Singh et al. 2013). Collectively, these observations suggest that AhR disrupts neurogenesis in a cell-specific and/or stage-specific manner. Exposure to high doses of BPA inhibited C17.2 neural progenitor cell proliferation and induced apoptosis (Kim et al. 2009). In contrast, low-dose exposure to BPA increased the number and length of neurites, suggesting that BPA could decrease the neural progenitor cell pool by promoting their differentiation (Kim et al. 2009).

The EDC 4-NP also regulated neural stem cell (NSC) survival and proliferation (Kudo et al. 2004). 4-NP exposure inhibited murine NSC proliferation in a dosedependent manner by inducing $\mathrm{G} 2 / \mathrm{M}$ phase arrest, downregulating cyclin A and B1 expression and promoting apoptosis. Furthermore, 4-NP inhibited the growth of NSCs at a lower concentration when compared with BPA, butyl benzyl phthalate (BBP), di- $n$-butyl phthalate (DBP), and DEHP (Kudo et al. 2004). Interestingly, BPA promoted neurosphere formation and immature neuron cell growth, suggesting that its activity could maintain in

Published by Bioscientifica Ltd. 
part the stem cell characteristics of NSCs. This study suggested that modulation of NSC 'stemness', growth, and differentiation was EDC dependent. Furthermore, NSCs in the early stages of differentiation were more sensitive to endocrine disruption than undifferentiated neurospheres or differentiated neurons (Kudo et al. 2004).

Primary cerebral cortical neurons cultured from 1 dayold rats born from mothers exposed to the organic pollutant 2,3,7,8-tetrachlorodibenzo-p-dioxin (TCDD) showed decreased cell viability, increased apoptosis, and decreased dendrite outgrowth as compared with control cells (Tomasini et al. 2012). These changes were associated with impairment in cortical glutamate transmission and resulted in decreased $\left[{ }^{3} \mathrm{H}\right]$ glutamate uptake that persisted into adult life (Tomasini et al. 2012). Primary neuronal cultures obtained from cerebral cortex of neonatal rats born to dams treated with methylmercury also exhibited decreased cell viability, increased apoptosis or necrosis, and abnormal neurite outgrowth. Long-term memory in the offspring was impaired (Ferraro et al. 2009). Taken together, these results suggest that prenatal exposure to EDCs such as TCDD or methylmercury alters cortical neuron development and promotes long-term glutamate and cognitive dysfunction respectively.

\section{Skeletal formation and bone remodeling}

Bone is an endocrine target tissue that is sensitive to numerous EDCs. Exposure to tributyltin chloride (TBT) in utero caused inhibition of calcification of the supraoccipital bone in embryonic day 17.5 fetuses. In vitro analysis suggested that TBT reduced alkaline phosphatase (ALPase) activity, the rate of calcium deposition, and expression of differentiation markers ALPase and osteocalcin in rat calvarial osteoblast-like cells (ROB cells). The TBT metabolite monobutyltin trichloride (MBT) did not affect fetal skeleton development or osteoblast differentiation of ROB cells (Tsukamoto et al. 2004). In mouse embryonic molar development, TBT impaired dentin mineralization and enamel formation, thereby reducing tooth size (Salmela et al. 2008). Furthermore, TBT differentially modulated genes associated with mineralization, e.g., decreasing osteocalcin expression in odontoblasts but increasing osteopontin in the epithelial cells of the enamel organ (Salmela et al. 2012). These observations indicate that TBT, not MBT, can disrupt the process of bone deposition and remodeling.

Trabecular bone mineral density in the female rat developing tibia decreased upon exposure to the brominated FR HBCD (van der Ven et al. 2009).
HBCD exposure also decreased bone length in males and females, and decreased total mineral content, total area, cortical area, and cortical thickness in males (van der Ven et al. 2009). TH-related effects included decreased circulating thyroxine $\left(\mathrm{T}_{4}\right)$ and increased TSH levels (van der Ven et al. 2009). Although in utero exposure to the brominated FR tetrabromobisphenol-A exhibited similar effects in decreasing circulating $\mathrm{T}_{4}$ levels, bone development was not disrupted (Van der Ven et al. 2008). These studies imply that the effects of FR exposure on bone development are gender- and flame-retardant specific.

Bone development is also responsive to the agricultural fungicide triphenyltin-hydroxide (TPTH) and alkylphenols. In a toxicity study, exposure of TPTH was not overtly toxic to pregnant mouse females (Sarpa et al. 2007). However, TPTH was considerably toxic to the developing pups as seen in the increased rate of embryo lethality. In those pups which did survive, developmental abnormalities included skeletal defects, e.g., increased incidence of cleft palate, palatine bone defects, and fetal skeleton variations (poorly ossified and misshapen skull bones) as well as malformations of the first (ossified cartilage and bent Atlas) and the second (misshapen Axis) cervical vertebrae (Sarpa et al. 2007). Alkylphenols are EDCs which exhibit estrogenic effects. NP and OP inhibited the formation of osteoclast cells in osteogenic stromal ST2 cells when cocultured with mouse spleen cells or mouse bone marrow cells, but did not affect the proliferation and differentiation of rat calvarial osteoblast-like cells (Hagiwara et al. 2008). In utero, exposure to NP or OP increased ossification in the pup sternebrae. In contrast, $\beta$-estradiol at did not affect osteoclast cell formation, suggesting that alkylphenols affected bone formation through non-estrogenic mechanisms (Hagiwara et al. 2008). Collectively, FR, TPTH, and alkylphenols disrupt the systemic hormonal regulation of skeleton formation and bone remodeling, suggesting that their target cells are bone stem/progenitor cells. The mechanisms by which these EDCs disrupt bone stem/progenitor cell proliferation, differentiation, and function remain to be investigated.

\section{Immune cell differentiation}

Indoor phthalate exposure has been correlated to increased incidence and severity of asthma in children and adults. To evaluate the effects of MEPH exposure on immune cell differentiation, the partially differentiated monocyte-macrophage cell line RAW264.7 was treated with increasing concentrations of MEHP.

Published by Bioscientifica Ltd. 
Exposure to MEHP increased tumor necrosis factor $\alpha$ (TNF- $\alpha$ ) release, promoted a change in cellular morphology to an elongated spindle-like appearance, and increased expression of the macrophage differentiation marker CD163. Western blot analysis indicated that MEHP induced p38 and Akt phosphorylation. Blocking these activities with specific inhibitors revealed that both p38 and phosphoinositide-3 (PI3) kinase/Akt signaling were involved in the release of TNF- $\alpha$, whereas only PI3 kinase promoted differentiation. Furthermore, PPAR $\alpha$ and $\beta$ inhibitors decreased differentiation but did not affect TNF- $\alpha$ release. Thus, MEHP promoted differentiation of RAW264.7 cells into M2-like macrophages through modulation of multiple signaling pathways (Bolling et al. 2012).

\section{Generation of cardiovascular tissue}

Acute ischemic injury and chronic cardiomyopathies can cause irreversible loss of normally functioning cardiac tissue (Schoenhard \& Hatzopoulos 2010). Treatment of heart disease using cellular therapy could improve ventricular function after injury. The pool of ES cellderived cardiac cells available for transplant could be enriched by culturing embryoid bodies with specific growth factors or small molecules which directed differentiation toward cardiovascular phenotypes (Schoenhard $\&$ Hatzopoulos 2010). Using this approach, xenoestrogens such as 4-tert-OP and 4-NP inhibited ES cell differentiation state by inducing Oct4 expression (Jung et al. 2010). TCDD-aryl hydrocarbons receptor (AhR) interactions also inhibited differentiation by downregulating the expression of the cardiomyocyte marker cTn-T and inhibiting the cardiac beating phenotype (Wang et al. 2010). These EDCs were therefore capable of directing differentiation toward a cardiovascular phenotype.

\section{Mammary gland development}

In vivo studies have shown that normal mammary gland development occurs through the reciprocal interactions between mesenchyme and epithelium. BPA is reported to activate estrogen receptor (ER) signaling in the primary mesenchyme, thereby inducing adipocyte differentiation in periductal stroma and fat pad and promoting ductal elongation and branching (reviewed in detail by Soto et al. (2013)). To determine the mechanisms by which BPA exposure modulates mammary gland morphogenesis at the cellular level, the human ES cells X-01 were cultured in the three-dimensional mammosphere assay in the presence of differentiation medium and increasing concentrations of BPA (Yang et al. 2013). Exposure to BPA upregulated the expression of Oct 4 and Nanog in a dosedependent manner. Furthermore, BPA, but not estradiol, downregulated E-cadherin expression, suggesting that regulation of E-cadherin expression occurred through an estrogen-independent mechanism (Yang et al. 2013). Together, these observations suggest that BPA disrupts differentiation by promoting a stem cell phenotype.

\section{Embryonic prostate gland development}

Exposure to endocrine disruptors is thought to influence the development of the embryonic prostate gland. In an animal study, it was shown that the fungicide Vinclozolin caused male reproductive tract atrophy in adult rodents through its antiandrogenic activity (Kavlock \& Cummings 2005). However, there remains a significant gap in our knowledge on the effects of EDCs on prostate development at the cellular level. For example, the effects of environmental EDCs on the hierarchy of transcriptional controls and signaling cascades which determine prostate organ development as well as commitment of progenitor cells to produce differentiated prostatic epithelial cells are unknown.

\section{Developmental programing of adipogenesis and obesity}

Adipose tissue is an endocrine organ which secretes protein hormones, e.g., leptin, and plays a central role in the regulation of metabolism (Kershaw \& Flier 2004). Altering the natural hormonal microenvironment during development could have profound effects on adipocyte cell specification, function, and the development of obesity (Wu et al. 2012). Clinical, epidemiological, and biological studies indicate that obesity is programed during the intrauterine period and in early life. These observations have brought about the obesogen hypothesis, which states that EDCs function as obesogens to promote adipogenesis thereby increasing the number of adipocytes before the establishment of the adipocyte compartment and adulthood (Grun \& Blumberg 2006).

Several endocrine disruptors are known to modulate the mechanisms by which multipotent mesenchymal stem cells (MSCs) differentiate into adipocytes. The organic TBT compounds are used in biocides to control a broad spectrum of organisms. Exposure of C57BL/6 mouse pups to TBT in utero increased adipose tissues in mammary and inguinal glands and epididymal fat pads (Grun et al. 2006). Exposure of Xenopus laevis tadpoles to TBT at environmentally low doses (1-10 nM) increased ectopic adipocyte formation posterior to the fat bodies in

Published by Bioscientifica Ltd. 
and around the gonads of males and females. At the highest TBT dose tested $(10 \mathrm{nM})$, testicular tissue was interspersed or replaced by adipocytes, suggesting that TBT could induce adipogenesis at the expense of other cell types (Grun et al. 2006). Similarly, exposure to the retinoid X receptor (RXR) and peroxisome proliferatoractivated receptor $\gamma$ (PPAR $\gamma$ ) ligands AGN195203 and troglitazone, respectively, also increased ectopic adipocyte formation, suggesting that TBT modulated MSC programing through RXR:PPAR $\gamma$ activation (Grun et al. 2006).

Other studies report that adipocyte differentiation is regulated by $\operatorname{PPAR} \gamma$ signaling. Multipotent adiposederived stromal stem cells (ADSCs) isolated from white adipose tissue of mice exposed to TBT in utero showed enhanced lipid accumulation and increased expression of PPAR $\gamma$ target genes, e.g., fatty acid-binding protein 4 (Fapb4; Kirchner et al. 2010). In vitro exposure of human and mouse ADSCs to TBT or the PPAR $\gamma$ activator rosiglitazone increased adipogenesis, cellular lipid content, and expression of adipogenic genes. These effects were inhibited by the addition of the PPAR $\gamma$ antagonist T0070907, suggesting that PPAR $\gamma$ promoted the TBT and rosiglitazone-mediated effects on adipocyte differentiation (Kirchner et al. 2010). In addition, TBT directed differentiation of 3T3-L1 embryonic murine preadipocyte fibroblast cells into adipocytes through PPAR $\gamma: \operatorname{RXR} \alpha$ signaling (Grun et al. 2006). Thus, TBT could regulate the stem cell compartment by directing MSC differentiation.

Adipogenesis is regulated by exposure to numerous EDCs, including BPA, bis(2-ethyl-hexyl)phthalate (DEHP), parabens, and FRs. The Biemann study investigated the effects of BPA, DEHP, and TBT during early adipogenic commitment and differentiation using the pluripotent CGR8 ESC and murine MSC C3H/10T1/2 cell lines (Biemann et al. 2011). Exposure to BPA, DEHP, and TBT did not affect adipogenesis in ESCs. However, during the undifferentiated MSC growth phase, exposure to BPA $(10 \mu \mathrm{M})$ reduced adipocyte differentiation and decreased expression of the adipogenic markers, FABP4, PPAR $\gamma 2$, LPL, and adiponectin. In contrast, TBT increased the number of adipocytes, TG content, and expression of adipocyte-specific gene. Exposure to DEHP had no effect. During the induction interval, BPA remained ineffective while TBT and DEHP increased the number of adipocytes, triglyceride content, and adipocyte-specific mRNA expression. Finally during terminal differentiation, only TBT promoted adipogenic differentiation while BPA or DEHP remained ineffective (Biemann et al. 2011). This study demonstrated that EDCs can cooperate in a temporal manner to direct adipocyte differentiation.
Chamorro-Garcia et al. (2012) reported that while BPA failed to promote adipogenesis in MSCs, BPA could induce adipogenesis in 3T3-L1 cells. Furthermore, the BPA derivate BPA diglyceraldyl ether (BADGE) was capable of inducing adipogenesis in human and mouse MSCs as well as in mouse 3T3-L1 preadipocytes. Interestingly, neither BPA nor BADGE activity could be blocked by PPAR $\gamma$ antagonists, nor did BPA or BADGE induce or antagonize RXR or PPAR $\gamma$ activity in transient transfection assays. Collectively, these observations indicate that BPA, TBT and DEHP, and TBT modulate adipogenic commitment and differentiation in a stage- and compound-specific manner through PPAR $\gamma$-dependent/independent signaling.

Parabens are alkyl esters of $p$-hydroxybenzoic acid that are used primarily for their bactericidal and fungicidal properties in cosmetics, toiletries, pharmaceuticals, and food. Parabens (butylparaben and benzylparaben in particular) promoted adipogenesis in human ADSCs. In murine 3T3-L1 cells, parabens induced adipocyte differentiation through PPAR $\gamma$ as well as glucocorticoid receptor-like signaling (Hu et al. 2013). In contrast, the paraben metabolite 4-hydroxybenzoic acid was inactive in the promotion of 3T3-L1 adipocyte differentiation (Hu et al. 2013).

While transcriptional regulation of MSCs appears to be a major driving force in the initiation of in utero and perinatal development of obesity, MSCs could also be biased toward differentiation into an adipocyte lineage through epigenetic modifications of the genome. Prenatal exposure of mouse ADSCs to TBT resulted in hypomethylation of the promoter/enhancer region of the Fapb4 locus and consequently overexpression of Fapb4 (Kirchner et al. 2010).

\section{Endocrine-disrupting activity and adult stem/progenitor cell function}

Adult stem/progenitor cells are thought to reside in niches within a tissue or organ. Their primary role is to maintain and repair the tissues in which they are found. Thus adult stem/progenitor cells are undifferentiated cells which differentiate into all, or a limited number, of the major specialized cell types of a given tissue or organ. While ESCs are defined by their derivation from the preimplantationstage embryo, the origin of adult stem/progenitor cells in different mature tissues is still under investigation.

Cell-sorting strategies to isolate the side fractions containing adult stem/progenitor cells commonly use cell surface markers expressed in ES or ES-derived progenitor cells. For example, Trop2, CD44, and CD49f have been used to isolate enriched stem cell-like populations from

Published by Bioscientifica Ltd. 
normal primary human prostate epithelial cells (Hu et al. 2012). Exposure of these cells to BPA, dioxin, or $E_{2}$ increased the percentage of prostate stem/progenitor cells in the side population, suggesting that these EDCs promoted self-renewal (Hu et al. 2012). In contrast, sodium arsenite markedly decreased prostasphere number and size (Hu et al. 2012). Similarly, treatment of mouse adult stem/progenitor cells with cadmium inhibited cell growth and sphere formation (Jiang et al. 2011). Thus sodium arsenite and cadmium appeared to inhibit selfrenewal. Other EDCs including TCDD and pesticide mixtures disrupted differentiation in hematopoietic stem cells and bone marrow progenitor cells respectively (Sakai et al. 2003, Chatterjee et al. 2013).

EDCs also dysregulate the sequential differentiation program in adult stem/progenitor cells. Exposure to TCDD inhibited oligodendroglial lineage potential, resulting in a lower percentage of glial fibrillary acid protein-positive cells (Fernandez et al. 2010). Furthermore, oligodendroglial maturation was inhibited as indicated by a decrease in CNPase-positive oligodendrocytes (Fernandez et al. 2010). Exposure to the FR BDE-209 compromised adult NSC differentiation by inhibiting neurite outgrowth and neuron differentiation, but promoting glial cell differentiation (Zhang et al. 2010).

In summary, the activities of EDCs, e.g., BPA, dioxin, $\mathrm{E}_{2}$, TCDD and FRs can modify the self-renewal and differentiation programs in tissue-derived adult stem/ progenitor cells. These mechanisms parallel those observed in ESC-derived progenitor cells. Disruption of the adult stem/progenitor cell self-renewal and differentiation could impact normal cell replacement, tissue repair following injury, and initiation of tumorigenesis.

\section{Endocrine disruptors and CSCs}

CSCs are a subpopulation of cancer cells which can initiate tumorigenesis by undergoing self-renewal and differentiation, similar to that observed in normal stem cells (Kasper 2008). The majority of cancer cells, however, exhibits limited proliferation potential and appears more differentiated (Rosen \& Jordan 2009). Epidemiological and experimental studies support the hypothesis that EDCs increase the risk of developing cancer, especially in organs that are highly sensitive to endocrine regulation. Yet few studies have addressed the potential effects of EDCs on CSCs.

Phthalates are associated with breast cancer risk (Lopez-Carrillo et al. 2010, Hsieh et al. 2012a,b). BBP and DBP induced EMT in R2d cells, an estrogen-responsive breast stem cell line. In addition, phthalate-mediated EMT, cell migration, and cell invasion required ER and histone deacetylase 6 (HDAC6) activities (Hsieh et al. $2012 a, b)$. These observations indicate that phthalates promote a metastatic phenotype.

A further mechanism by which EDCs could increase breast cancer risk is through heritable silencing. Methylation screening demonstrated that pre-exposure of progenitor-derived epithelial cells to estrogen caused DNA hypermethylation and transcriptional silencing of tumor suppressor genes, e.g., RUNX3 (Cheng et al. 2008). Furthermore, estrogen-induced hypermethylation of $R U N X 3$ was observed in breast tumors as well as in adjacent tissues which appeared histologically normal.

Estrogens may exert endocrine disruption activities that reprogram normal adult prostate stem/progenitor cells (Hu et al. 2012). Cultured prostaspheres composed of prostate stem/progenitor cells expressing $E R \alpha, E R \beta$, and GPR30 (GPER1) proliferated in response to low-dose estradiol and BPA, increasing the number of stem-like cells in the side populations. Prostasphere cells also expressed RARs, RXRs, and AHR. Low-dose retinoic acid stimulated prostasphere cell differentiation. In contrast, arsenic and dioxin perturbed their growth (Hu et al. 2012).

Exposure to arsenic is reported to transform normal prostate stem cells into CSCs to promote tumor growth (Tokar et al. 2011). The Xu study demonstrated that arsenic-transformed prostate epithelial cells (termed MEC) could impart a cancer phenotype on nearby WPEstem cells (termed NSCs) during noncontact coculture (Xu et al. 2012). NSC transformation was observed through increased MMP activity and cell invasion and downregulation of PTEN expression. This mechanism was thought to amplify CSC number (Xu et al. 2012). Similarly, CD34-positive cells isolated from a human skin keratinocyte line and exposed to inorganic arsenic appeared to contain proportionally more putative CSCs than normal stem cells isolated from control cells (Sun et al. 2012).

Together, this limited number of studies suggests that CSCs derived from human breast, prostate, and skin are direct targets for EDC activity.

\section{Concluding remarks}

Maternal and early childhood exposures to EDCs have been shown to impair physical and cognitive development, organogenesis, and sexual differentiation.

Published by Bioscientifica Ltd. 
Pluripotent ESCs may be manipulated to produce progenitor cell types which differentiate into specific cell lineages. The ES cell-derived cardiac cell model was used to investigate xenoestrogen (Jung et al. 2010) and dioxin (Wang et al. 2010, Chatterjee et al. 2013) activities in disrupting cardiomyocyte differentiation. Multipotent MSCs were used to study the underlying processes which regulate the developmental programing of adipogenesis and obesity (Grun et al. 2006, Kirchner et al. 2010, Biemann et al. 2011). Thus, embryonic cells exhibiting stem cell-like properties could be utilized to study the processes which are dysregulated by EDCs in utero and during early childhood. Adult stem cells could be applied to study the chronic effects of EDC exposure on normal cell turnover and tissue repair following injury. Furthermore, cancer cells exhibiting stem cell-like properties could be used to investigate the role of EDC exposure on promoting expansion of stem cell-like cancer cells which drive tumorigenesis, cancer progression, metastasis, and therapeutic resistance.

Despite advances in cell culture technology, relatively little attention has been paid to the cell types which are direct targets of EDC exposure. In vitro models such as embryoid bodies, sphere formation, three-dimensional cell culture systems, and engineered tissues allow more in-depth analysis of physiological processes that range from early stages of embryogenesis to a functioning tissue. Therefore, these approaches could be employed to study the mechanisms underlying the effects of EDC exposure. Furthermore, they could be used to identify pathways which are activated or inhibited by exposure to EDCs. These cells could also be developed into rapid in vitro screening assays for toxicity testing. In summary, developing systems for studying the molecular mechanisms that regulate self-renewal and differentiation of normal stem cells, progenitor cells, and CSCs could be powerful models for assessing the effects of environmental EDCs.

\section{Declaration of interest}

The authors declare that there is no conflict of interest that could be perceived as prejudicing the impartiality of the review.

\section{Funding}

This review did not receive any specific grant from any funding agency in the public, commercial, or not-for-profit sector.

\section{Author contribution statement}

E Kopras, V Potluri and M-L Bermudez contributed equally to this work.

\section{References}

Ahn HJ, An BS, Jung EM, Yang H, Choi KC \& Jeung EB 2012 Parabens inhibit the early phase of folliculogenesis and steroidogenesis in the ovaries of neonatal rats. Molecular Reproduction and Development 79 626-636. (doi:10.1002/mrd.22070)

Annab LA, Bortner CD, Sifre MI, Collins JM, Shah RR, Dixon D, Karimi Kinyamu H \& Archer TK 2012 Differential responses to retinoic acid and endocrine disruptor compounds of subpopulations within human embryonic stem cell lines. Differentiation 84 330-343. (doi:10.1016/ j.diff.2012.07.006)

Aoki T \& Takada T 2012 Bisphenol A modulates germ cell differentiation and retinoic acid signaling in mouse ES cells. Reproductive Toxicology $\mathbf{3 4}$ 463-470. (doi:10.1016/j.reprotox.2012.06.001)

Biemann R, Navarrete Santos A, Navarrete Santos A, Riemann D, Knelangen J, Bluher M, Koch H \& Fischer B 2011 Endocrine disrupting chemicals affect the adipogenic differentiation of mesenchymal stem cells in distinct ontogenetic windows. Biochemical and Biophysical Research Communications 417 747-752. (doi:10.1016/j.bbrc.2011.12.028)

Birnbaum LS 2013 When environmental chemicals act like uncontrolled medicine. Trends in Endocrinology and Metabolism 24 321-323. (doi:10.1016/j.tem.2012.12.005)

Bolling AK, Ovrevik J, Samuelsen JT, Holme JA, Rakkestad KE, Mathisen GH Paulsen RE, Korsnes MS \& Becher R 2012 Mono-2-ethylhexylphthalate (MEHP) induces TNF- $\alpha$ release and macrophage differentiation through different signalling pathways in RAW264.7 cells. Toxicology Letters 209 43-50. (doi:10.1016/j.toxlet.2011.11.016)

Chamorro-Garcia R, Kirchner S, Li X, Janesick A, Casey SC, Chow C \& Blumberg B 2012 Bisphenol A diglycidyl ether induces adipogenic differentiation of multipotent stromal stem cells through a peroxisome proliferator-activated receptor $\gamma$-independent mechanism. Environmental Health Perspectives 120 984-989. (doi:10.1289/ehp.1205063)

Chatterjee S, Basak P, Chaklader M, Das P, Pereira JA, Chaudhuri S \& Law S 2013 Pesticide induced marrow toxicity and effects on marrow cell population and on hematopoietic stroma. Experimental and Toxicologic Pathology 65 287-295. (doi:10.1016/j.etp.2011.09.002)

Chen JX, Xu LL, Mei JH, Yu XB, Kuang HB, Liu HY, Wu YJ \& Wang JL 2012 Involvement of neuropathy target esterase in tri-ortho-cresyl phosphate-induced testicular spermatogenesis failure and growth inhibition of spermatogonial stem cells in mice. Toxicology Letters 211 54-61. (doi:10.1016/j.toxlet.2012.03.004)

Cheng AS, Culhane AC, Chan MW, Venkataramu CR, Ehrich M, Nasir A, Rodriguez BA, Liu J, Yan PS, Quackenbush J et al. 2008 Epithelial progeny of estrogen-exposed breast progenitor cells display a cancerlike methylome. Cancer Research 68 1786-1796. (doi:10.1158/00085472.CAN-07-5547)

Erkekoglu P, Zeybek ND, Giray B, Asan E \& Hincal F 2012 The effects of di(2-ethylhexyl)phthalate exposure and selenium nutrition on Sertoli cell vimentin structure and germ-cell apoptosis in rat testis. Archives of Environmental Contamination and Toxicology 62 539-547. (doi:10.1007/ s00244-011-9712-9)

Fernandez M, Paradisi M, D’Intino G, Del Vecchio G, Sivilia S, Giardino L \& Calza L 2010 A single prenatal exposure to the endocrine disruptor 2,3,7,8-tetrachlorodibenzo- $p$-dioxin alters developmental myelination and remyelination potential in the rat brain. Journal of Neurochemistry 115 897-909. (doi:10.1111/j.1471-4159.2010.06974.x)

Ferraro L, Tomasini MC, Tanganelli S, Mazza R, Coluccia A, Carratu MR, Gaetani S, Cuomo V \& Antonelli T 2009 Developmental exposure to methylmercury elicits early cell death in the cerebral cortex and longterm memory deficits in the rat. International Journal of Developmental Neuroscience 27 165-174. (doi:10.1016/j.ijdevneu.2008.11.004)

Fritsche E, Cline JE, Nguyen NH, Scanlan TS \& Abel J 2005 Polychlorinated biphenyls disturb differentiation of normal human neural progenitor cells: clue for involvement of thyroid hormone receptors. Environmental Health Perspectives 113 871-876. (doi:10.1289/ehp.7793) 
Gilbert ME, Rovet J, Chen Z \& Koibuchi N 2012 Developmental thyroid hormone disruption: prevalence, environmental contaminants and neurodevelopmental consequences. Neurotoxicology 33 842-852. (doi:10.1016/j.neuro.2011.11.005)

Gotz M \& Huttner WB 2005 The cell biology of neurogenesis. Nature Reviews. Molecular Cell Biology 6 777-788. (doi:10.1038/nrm1739)

Grun F \& Blumberg B 2006 Environmental obesogens: organotins and endocrine disruption via nuclear receptor signaling. Endocrinology 147 S50-S55. (doi:10.1210/en.2005-1129)

Grun F, Watanabe H, Zamanian Z, Maeda L, Arima K, Cubacha R, Gardiner DM, Kanno J, Iguchi T \& Blumberg B 2006 Endocrinedisrupting organotin compounds are potent inducers of adipogenesis in vertebrates. Molecular Endocrinology 20 2141-2155. (doi:10.1210/ me.2005-0367)

Guerrero-Bosagna C, Covert TR, Haque MM, Settles M, Nilsson EE, Anway MD \& Skinner MK 2012 Epigenetic transgenerational inheritance of vinclozolin induced mouse adult onset disease and associated sperm epigenome biomarkers. Reproductive Toxicology 34 694-707. (doi:10.1016/ j.reprotox.2012.09.005)

Hagiwara H, Sugizaki T, Tsukamoto Y, Senoh E, Goto T \& Ishihara Y 2008 Effects of alkylphenols on bone metabolism in vivo and in vitro. Toxicology Letters 181 13-18. (doi:10.1016/j.toxlet.2008.06.863)

Hsieh TH, Tsai CF, Hsu CY, Kuo PL, Hsi E, Suen JL, Hung CH, Lee JN, Chai CY, Wang SC et al. 2012a $n$-Butyl benzyl phthalate promotes breast cancer progression by inducing expression of lymphoid enhancer factor 1 . PLoS ONE 7 e42750. (doi:10.1371/journal.pone.0042750)

Hsieh TH, Tsai CF, Hsu CY, Kuo PL, Lee JN, Chai CY, Hou MF, Chang CC, Long CY, Ko YC et al. $2012 b$ Phthalates stimulate the epithelial to mesenchymal transition through an HDAC6-dependent mechanism in human breast epithelial stem cells. Toxicological Sciences 128 365-376. (doi:10.1093/toxsci/kfs163)

Hu GX, Lian QQ, Ge RS, Hardy DO \& Li XK 2009 Phthalate-induced testicular dysgenesis syndrome: Leydig cell influence. Trends in Endocrinology and Metabolism 20 139-145. (doi:10.1016/j.tem. 2008.12.001)

Hu WY, Shi GB, Hu DP, Nelles JL \& Prins GS 2012 Actions of estrogens and endocrine disrupting chemicals on human prostate stem/progenitor cells and prostate cancer risk. Molecular and Cellular Endocrinology 354 63-73. (doi:10.1016/j.mce.2011.08.032)

Hu P, Chen X, Whitener RJ, Boder ET, Jones JO, Porollo A, Chen J \& Zhao L 2013 Effects of parabens on adipocyte differentiation. Toxicological Sciences 131 56-70. (doi:10.1093/toxsci/kfs262)

Ibhazehiebo K, Iwasaki T, Kimura-Kuroda J, Miyazaki W, Shimokawa N \& Koibuchi N 2011 $a$ Disruption of thyroid hormone receptor-mediated transcription and thyroid hormone-induced Purkinje cell dendrite arborization by polybrominated diphenyl ethers. Environmental Health Perspectives 119 168-175. (doi:10.1289/ehp.1002065)

Ibhazehiebo K, Iwasaki T, Okano-Uchida T, Shimokawa N, Ishizaki Y \& Koibuchi N $2011 b$ Suppression of thyroid hormone receptor-mediated transcription and disruption of thyroid hormone-induced cerebellar morphogenesis by the polybrominated biphenyl mixture, BP-6. Neurotoxicology 32 400-409. (doi:10.1016/j.neuro.2011.02.008)

Ibhazehiebo K, Iwasaki T, Shimokawa N \& Koibuchi N 2011c 1,2,5,6,9,10$\alpha$ Hexabromocyclododecane (HBCD) impairs thyroid hormoneinduced dendrite arborization of Purkinje cells and suppresses thyroid hormone receptor-mediated transcription. Cerebellum 10 22-31. (doi:10.1007/s12311-010-0218-1)

Ibhazehiebo K, Iwasaki T, Xu M, Shimokawa N \& Koibuchi N 2011d Brain-derived neurotrophic factor (BDNF) ameliorates the suppression of thyroid hormone-induced granule cell neurite extension by hexabromocyclododecane (HBCD). Neuroscience Letters 493 1-7. (doi:10.1016/j.neulet.2011.01.062)

Jensen J, Hyllner J \& Bjorquist P 2009 Human embryonic stem cell technologies and drug discovery. Journal of Cellular Physiology 219 513-519. (doi:10.1002/jcp.21732)
Jiang G, Xu L, Zhang B \& Wu L 2011 Effects of cadmium on proliferation and self-renewal activity of prostate stem/progenitor cells. Environmental Toxicology and Pharmacology 32 275-284. (doi:10.1016/ j.etap.2011.05.015)

Jung EM, Choi KC, Yu FH \& Jeung EB 2010 Effects of $17 \beta$-estradiol and xenoestrogens on mouse embryonic stem cells. Toxicology In Vitro 24 1538-1545. (doi:10.1016/j.tiv.2010.06.019)

Kasper S 2008 Stem cells: the root of prostate cancer? Journal of Cellular Physiology 216 332-336. (doi:10.1002/jcp.21489)

Kavlock R \& Cummings A 2005 Mode of action: inhibition of androgen receptor function-vinclozolin-induced malformations in reproductive development. Critical Reviews in Toxicology 35 721-726. (doi:10.1080/ 10408440591007377)

Kershaw EE \& Flier JS 2004 Adipose tissue as an endocrine organ. Journal of Clinical Endocrinology and Metabolism 89 2548-2556. (doi:10.1210/ jc.2004-0395)

Kim SK, Kim BK, Shim JH, Gil JE, Yoon YD \& Kim JH 2006 Nonylphenol and octylphenol-induced apoptosis in human embryonic stem cells is related to Fas-Fas ligand pathway. Toxicological Sciences 94 310-321. (doi:10.1093/toxsci/kfl114)

Kim K, Son TG, Park HR, Kim SJ, Kim HS, Kim HS, Kim TS, Jung KK, Han SY \& Lee J 2009 Potencies of bisphenol A on the neuronal differentiation and hippocampal neurogenesis. Journal of Toxicology and Environmental Health. Part A 72 1343-1351. (doi:10.1080/15287390903212501)

Kirchner S, Kieu T, Chow C, Casey S \& Blumberg B 2010 Prenatal exposure to the environmental obesogen tributyltin predisposes multipotent stem cells to become adipocytes. Molecular Endocrinology 24 526-539. (doi:10.1210/me.2009-0261)

Kojima H, Takeuchi S, Uramaru N, Sugihara K, Yoshida T \& Kitamura S 2009 Nuclear hormone receptor activity of polybrominated diphenyl ethers and their hydroxylated and methoxylated metabolites in transactivation assays using Chinese hamster ovary cells. Environmental Health Perspectives 117 1210-1218. (doi:10.1289/ehp.0900753)

Kristensen DM, Sonne SB, Ottesen AM, Perrett RM, Nielsen JE, Almstrup K, Skakkebaek NE, Leffers H \& Rajpert-De Meyts E 2008 Origin of pluripotent germ cell tumours: the role of microenvironment during embryonic development. Molecular and Cellular Endocrinology 288 111-118. (doi:10.1016/j.mce.2008.02.018)

Krtolica A \& Giritharan G 2010 Use of human embryonic stem cell-based models for male reproductive toxicity screening. Systems Biology in Reproductive Medicine 56 213-221. (doi:10.3109/19396368.2010. 486470)

Kudo C, Wada K, Masuda T, Yonemura T, Shibuya A, Fujimoto Y, Nakajima A, Niwa H \& Kamisaki Y 2004 Nonylphenol induces the death of neural stem cells due to activation of the caspase cascade and regulation of the cell cycle. Journal of Neurochemistry 88 1416-1423. (doi:10.1046/j.1471-4159.2003.02270.x)

Lopez-Carrillo L, Hernandez-Ramirez RU, Calafat AM, Torres-Sanchez L, Galvan-Portillo M, Needham LL, Ruiz-Ramos R \& Cebrian ME 2010 Exposure to phthalates and breast cancer risk in northern Mexico. Environmental Health Perspectives 118 539-544. (doi:10.1289/ ehp.0901091)

Odorico JS, Kaufman DS \& Thomson JA 2001 Multilineage differentiation from human embryonic stem cell lines. Stem Cells 19 193-204. (doi:10.1634/stemcells.19-3-193)

Piquet-Pellorce C, Dorval-Coiffec I, Pham MD \& Jegou B 2000 Leukemia inhibitory factor expression and regulation within the testis. Endocrinology 141 1136-1141. (doi:10.1210/en.141.3.1136)

Rosen JM \& Jordan CT 2009 The increasing complexity of the cancer stem cell paradigm. Science 324 1670-1673. (doi:10.1126/science.1171837)

Sakai R, Kajiume T, Inoue H, Kanno R, Miyazaki M, Ninomiya Y \& Kanno M 2003 TCDD treatment eliminates the long-term reconstitution activity of hematopoietic stem cells. Toxicological Sciences 72 84-91. (doi:10.1093/toxsci/kfg002)

Salmela E, Sahlberg C, Alaluusua S \& Lukinmaa PL 2008 Tributyltin impairs dentin mineralization and enamel formation in cultured mouse 
embryonic molar teeth. Toxicological Sciences 106 214-222. (doi:10.1093/toxsci/kfn156)

Salmela E, Alaluusua S, Sahlberg C \& Lukinmaa PL 2012 Tributyltin alters osteocalcin, matrix metalloproteinase 20 and dentin sialophosphoprotein gene expression in mineralizing mouse embryonic tooth in vitro. Cells, Tissues, Organs 195 287-295. (doi:10.1159/000327529)

Sarpa M, De-Carvalho RR, Delgado IF \& Paumgartten FJ 2007 Developmental toxicity of triphenyltin hydroxide in mice. Regulatory Toxicology and Pharmacology 49 43-52. (doi:10.1016/j.yrtph.2007.05.006)

Schoenhard JA \& Hatzopoulos AK 2010 Stem cell therapy: pieces of the puzzle. Journal of Cardiovascular Translational Research 3 49-60. (doi:10.1007/s12265-009-9148-z)

Schriks M, Roessig JM, Murk AJ \& Furlow JD 2007 Thyroid hormone receptor isoform selectivity of thyroid hormone disrupting compounds quantified with an in vitro reporter gene assay. Environmental Toxicology and Pharmacology 23 302-307. (doi:10.1016/j.etap.2006.11.007)

Sharpe RM 2006 Pathways of endocrine disruption during male sexual differentiation and masculinization. Best Practice \& Research. Clinical Endocrinology \& Metabolism 20 91-110. (doi:10.1016/j.beem.2005.09.005)

Singh AK, Kashyap MP, Kumar V, Tripathi VK, Yadav DK, Khan F, Jahan S, Khanna VK, Yadav S \& Pant AB 2013 3-Methylcholanthrene induces neurotoxicity in developing neurons derived from human CD34+ Thy $1+$ stem cells by activation of aryl hydrocarbon receptor. Neuromolecular Medicine 15 570-592. (doi:10.1007/s12017-013-8243-0)

Soto AM, Brisken C, Schaeberle C \& Sonnenschein C 2013 Does cancer start in the womb? Altered mammary gland development and predisposition to breast cancer due to in utero exposure to endocrine disruptors Journal of Mammary Gland Biology \& Neoplasia 18 199-208. (doi:10.1007/s10911-013-9293-5)

Sun Y, Tokar EJ \& Waalkes MP 2012 Overabundance of putative cancer stem cells in human skin keratinocyte cells malignantly transformed by arsenic. Toxicological Sciences 125 20-29. (doi:10.1093/toxsci/kfr282)

Tokar EJ, Qu W \& Waalkes MP 2011 Arsenic, stem cells, and the developmental basis of adult cancer. Toxicological Sciences 120 (Suppl 1) S192-S203. (doi:10.1093/toxsci/kfq342)

Tomasini MC, Beggiato S, Ferraro L, Tanganelli S, Marani L, Lorenzini L \& Antonelli T 2012 Prenatal exposure to 2,3,7,8-tetrachlorodibenzop-dioxin produces alterations in cortical neuron development and a long-term dysfunction of glutamate transmission in rat cerebral cortex. Neurochemistry International 61 759-766. (doi:10.1016/j.neuint. 2012.07.004)

Tsukamoto Y, Ishihara Y, Miyagawa-Tomita S \& Hagiwara H 2004 Inhibition of ossification in vivo and differentiation of osteoblasts in vitro by tributyltin. Biochemical Pharmacology 68 739-746. (doi:10.1016/j.bcp.2004.04.020)

Van der Ven LT, Van de Kuil T, Verhoef A, Verwer CM, Lilienthal H, Leonards PE, Schauer UM, Canton RF, Litens S, De Jong FH et al. 2008 Endocrine effects of tetrabromobisphenol-A (TBBPA) in Wistar rats as tested in a one-generation reproduction study and a subacute toxicity study. Toxicology 245 76-89. (doi:10.1016/j.tox.2007.12.009)

van der Ven LT, van de Kuil T, Leonards PE, Slob W, Lilienthal H, Litens S, Herlin M, Hakansson H, Canton RF, van den Berg M et al. 2009 Endocrine effects of hexabromocyclododecane (HBCD) in a onegeneration reproduction study in Wistar rats. Toxicology Letters 185 51-62. (doi:10.1016/j.toxlet.2008.12.003)

Wang Y, Fan Y \& Puga A 2010 Dioxin exposure disrupts the differentiation of mouse embryonic stem cells into cardiomyocytes. Toxicological Sciences 115 225-237. (doi:10.1093/toxsci/kfq038)

Wu L, Wang T, Ge Y, Cai X, Wang J \& Lin Y 2012 Secreted factors from adipose tissue increase adipogenic differentiation of mesenchymal stem cells. Cell Proliferation 45 311-319. (doi:10.1111/j.1365-2184. 2012.00823.x)

Xu Y, Tokar EJ, Sun Y \& Waalkes MP 2012 Arsenic-transformed malignant prostate epithelia can convert noncontiguous normal stem cells into an oncogenic phenotype. Environmental Health Perspectives 120 865-871. (doi:10.1289/ehp.1204987)

Yang L, Luo L, Ji W, Gong C, Wu D, Huang H, Liu Q, Xia B, Hu G, Zhang W et al. 2013 Effect of low dose bisphenol A on the early differentiation of human embryonic stem cells into mammary epithelial cells. Toxicology Letters 218 187-193. (doi:10.1016/j.toxlet.2013.01.026)

Yao PL, Lin YC \& Richburg JH 2009 TNF $\alpha$-mediated disruption of spermatogenesis in response to Sertoli cell injury in rodents is partially regulated by MMP2. Biology of Reproduction 80 581-589. (doi:10.1095/ biolreprod.108.073122)

Yao PL, Lin YC \& Richburg JH 2010 Mono-(2-ethylhexyl) phthalateinduced disruption of junctional complexes in the seminiferous epithelium of the rodent testis is mediated by MMP2. Biology of Reproduction 82 516-527. (doi:10.1095/biolreprod.109.080374)

Zhang Y, Ge R \& Hardy MP 2008 Androgen-forming stem Leydig cells: identification, function and therapeutic potential. Disease Markers 24 277-286. (doi:10.1155/2008/905025)

Zhang C, Liu X \& Chen D 2010 Role of brominated diphenly ether-209 in the differentiation of neural stem cells in vitro. International Journal of Developmental Neuroscience 28 497-502. (doi:10.1016/ j.ijdevneu.2010.06.002)

Received in final form 6 November 2013

Accepted 25 November 2013

Made available online as an Accepted Preprint

26 November 2013
(C) 2014 Society for Endocrinology Printed in Great Britain
Published by Bioscientifica Ltd. 